\title{
Influence of flow hydraulic characteristics on the ridge lower escarpment angle
}

\author{
Takhir Majidov*, and Nazir Ikramov \\ ${ }^{1}$ Tashkent Institute of Irrigation and Agricultural Mechanization Engineers, Tashkent, Uzbekistan
}

\begin{abstract}
In the riverbeds and canals that run on non-cohesive grounds, bedload sediments move in the ridges form. Ridge forms determine the flow rate of bedload sediments, hydraulic resistances, the types and rates of deformations in alluvial channels. The main elements of ridge formations are height, gentle and steep length with corresponding escarpments. The ridge's steep length and this corresponding escarpment change with changes in the flow hydraulic characteristics. With a change in the ridge's steep length and its steep escarpment, the hydraulic resistance of the channel, the flow rate of bedload sediments, the types, and the channel deformation rates change. In the laboratory, a series of experiments with different sediments compositions and diameters were carried out on the hydraulic tray to determine the main elements (total, gentle and steep length, and the ridge height) and the dynamic characteristics of the ridge formations and the flow hydraulic characteristics. Calculation formulas for determining the coefficient of the ridge lower escarpments with and without taking into account the angle of the natural ground escarpment under water and in the dry state, and the dependence of the steepness of the relative ridge on the relative flow velocity, are obtained. The obtained dependencies allow to accurately determine the geometric and dynamic characteristics of bedload ridges and the corresponding hydraulic characteristics that may define the view ridge formations, ridges resistance of the channel, and the flow rate of bedload sediments, and to design sustainable escarpments large channels.
\end{abstract}

\section{Introduction}

In the Republic of Uzbekistan, the riverbed of all large irrigation canals (Large Ferghana canal, Large Namangan canal, Large Andijan canal, Bozsu, Dargom, Amuzang, Tashsaka, Pakhta-arna, Kizketkan, etc.) is composed of various non-cohesive grounds. These noncohesive sediment grounds move in a suspended state and move along the bedload, which occurs mainly in the ridge form. These forms determine the flow rate of bedload sediments, hydraulic resistances, the types and rates of deformation in alluvial channels (1-6). The study of the mobility, shape, and size of ridge formations is one of the topical issues of the modern theory of the bedload sediments movement.

The main elements of ridge formations are height, gentle and steep length with corresponding escarpments. One of the characteristic elements of the ridge forms of moving

\footnotetext{
*Corresponding author: suvchi2001@yahoo.com
} 
sediments is the angle of the ridge lower escarpment -ctg $\varphi$, i.e., the ratio of the ridge steep length to its height. The ridges steep length and corresponding escarpment change with changes in the flow hydraulic characteristics, which leads to changes in the hydraulic resistances of the channel, flow rate of bedload sediment, the types, and rate of deformation of the channel.

Knowledge of the formation regularities and changes in time and space of the angle of the ridges' lower escarpments is important in addressing issues related to the definition of bedform types, the height of ridge formations, riverbed hydraulic resistances, and bedload sediments flow rate. Despite this, the scientific literature does not pay enough attention to the special study of this important geometric characteristic of the sediments' ridge forms.

In several works [7-14], it is noted that the value of the angle downstream side (ctg $\varphi$ ) for short ridges slightly less than the angle of repose $\left(\operatorname{ctg} \varphi_{0}\right)$ materials in water, due to the influence of the reverse flow in the vortex zone cellar ridge. At the same time, it is assumed that the value of the lower escarpment angle of remains constant for this form of ridges and does not depend on the flow hydraulic characteristics. The conclusions of some authors $(15,16)$ seem to be valid only for the ridges form that was obtained in their studies.

According to Hino (17), in the case of fully developed ridges, their spectrum is determined only by the lower escarpment coefficient, and the value of the latter does not depend on the flow hydraulic characteristics.

When studying statistical characteristics of sand waves, some authors (18) investigated the nature of the lower escarpment angles distribution and did not find the influence of the flow hydraulic characteristics on its value. The above works do not generalize the data obtained, do not conduct a quantitative and qualitative analysis of the works devoted to the ridges' lower escarpment, and the conclusions drawn are local in nature.

To determine the values of the lower escarpment angles in (19) for the first time conducted ridges experimental studies composed of sediments with the average particle diameter of $\mathrm{d}=0.23 \mathrm{~mm}$. Analyzing of experiments results involving materials of field studies and experimental data of other authors, he concluded that the angle of the ridges lower escarpment in changing their forms until antidune does not depend on the flow hydraulic characteristics and it is determined by the value of the relative density of noncohesive grounds:

$$
\operatorname{tg} \varphi=7.08 e^{0.19 \rho^{1}}
$$

here: $\rho^{1}=\rho_{\mathrm{s}}-\rho / \rho$ is relative ground density; $\rho_{\mathrm{s}}$ and $\rho$ is ground and water density.

The solid particle density of bedload sediments varies within narrow limits, from 2600 to $2700 \mathrm{~kg} / \mathrm{m}^{3}(20)$. According to (1), upon receipt appears to be used mostly experiments data authors (21), in which experimental materials density were varied in a wide range from 1050 to $2650 \mathrm{~kg} / \mathrm{m}^{3}$. If that the natural sediment density equals $2650 \mathrm{~kg} / \mathrm{m}^{3}$, the lower escarpments angle calculated by the formula (1) will be equal to the constant value that does not correspond to a conclusion about the ridges' lower escarpments variability formed from natural sediment.

Analysis of works $(8,15,22,23)$, dedicated to determining the angle of the lower escarpment ridge, shows that authors, without paying due attention to the flow hydraulic characteristics, influence the value of the lower escarpment angle, stated that the value of the lower escarpment angle is not constant and depends on bedload materials characteristics $(19,24-26)$.

\section{Materials and methods}


The purpose of conducted experimental studies was to evaluate change in the lower escarpment angle depending on the change in the flow hydraulic characteristics. Based on obtained dependencies, it will be possible to determine the ridge formations type, the riverbed ridge resistance, bedload sediments flow rate, and make it possible to design stable escarpments of large canals.

Due to the difficulty of measuring geometric dimensions in full-scale conditions, experiments were carried out in the laboratory on the hydraulic tray (Figure 1). The bedload sediments of the Chirchik river taken below the Gazalkent dam were used as experimental material. The method of conducting experiments was adopted close to the method used earlier by some researchers (27-30).

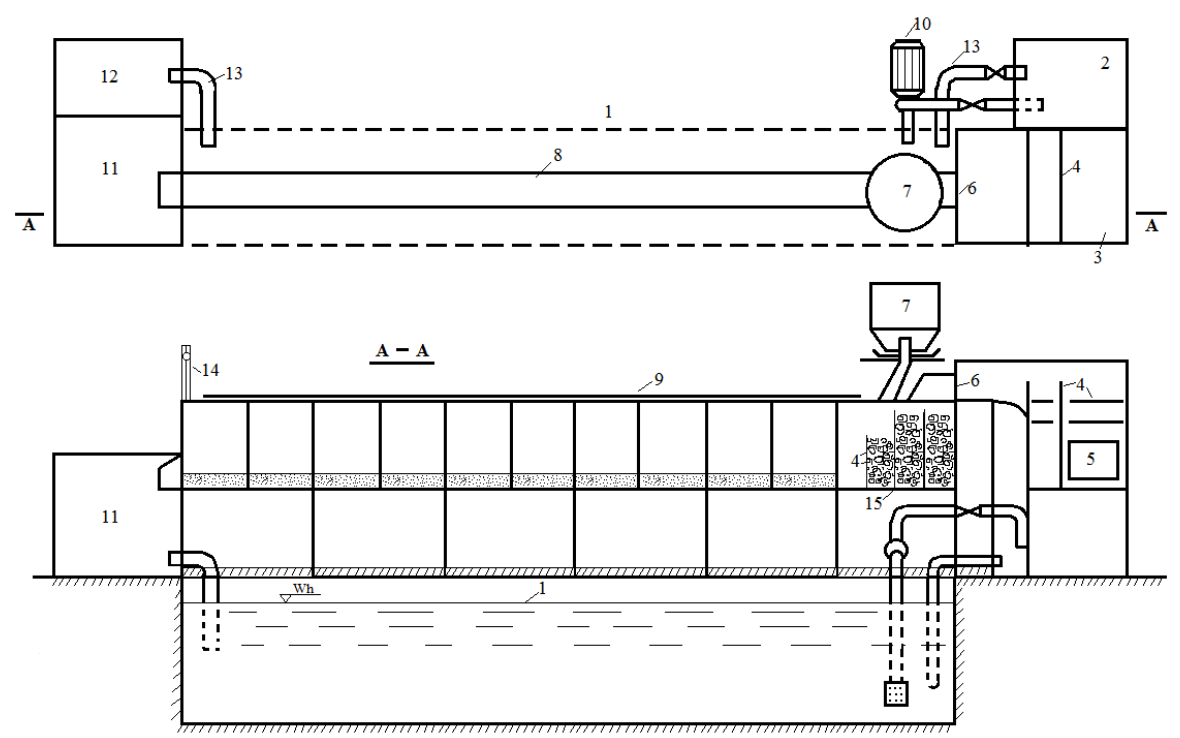

Fig. 1. Scheme of a flat glazed experimental unit:

1 is main pool; 2 is main tank; 3 is water intake tank; 4 are dampener grids; 5 is connecting pipe; 6 is spillway; 7 is dispenser; 8 is tray; 9 is rail; 10 is centrifugal pump; 11,12 is sump pool; 13 are return pipes; 14 is control panel; 15 are chips-dampers.

\section{Results and Discussion}

To determine the angle of the ridge lower escarpment in our experiments, we measured the length of the ridges' steep part, which is the escarpment projection on the horizontal axis. The value of the bedload escarpment angle was calculated by dividing the steep length by the ridge height (Figure 2):

$$
m_{2}=\operatorname{ctg} \varphi=\frac{l_{k}}{h_{r}}
$$

here: $\operatorname{ctg} \varphi$ is cotangent of the bedload escarpment angle (ridge lower escarpment coefficient); $l_{\kappa}$ and $h_{r}$ are steep length and ridge height. 


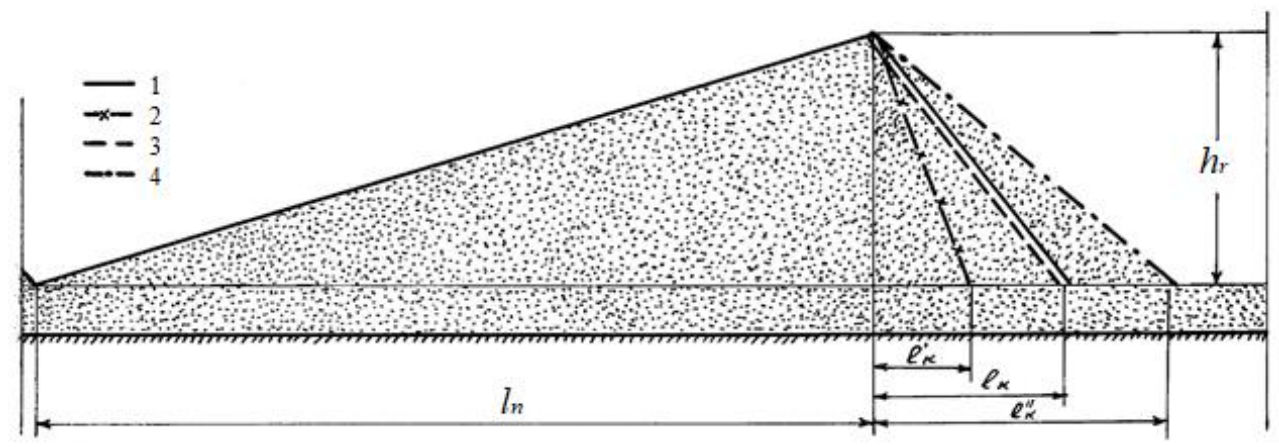

Fig. 2. Stages of the ridge lower escarpment formation $\left(\mathrm{m}_{K}\right): 1$ is coefficient of natural ground escarpment $m_{0} ; 2$ - at $\vartheta / \vartheta_{0}=1,0 \div 1,5, m_{K}>m_{0} ; 3$ - at $\vartheta / \vartheta_{0}=1,5 \div 1,6, m_{K}=m_{0} ; 4$ - at $\vartheta / \vartheta_{0}>1,6, m_{K}<m_{0}$.

To determine the ridge steep length, according to experimental data, the dependence graph is constructed $l_{K} / h_{r}=f\left(\vartheta / \vartheta_{0}\right)$ (Figure 3 ), which is approximated by the dependence:

$$
\frac{l_{k}}{h_{r}}=6,594\left(\frac{\vartheta}{\vartheta_{0}}\right)^{2}-27,26 \frac{\vartheta}{\vartheta_{0}}+29,1
$$

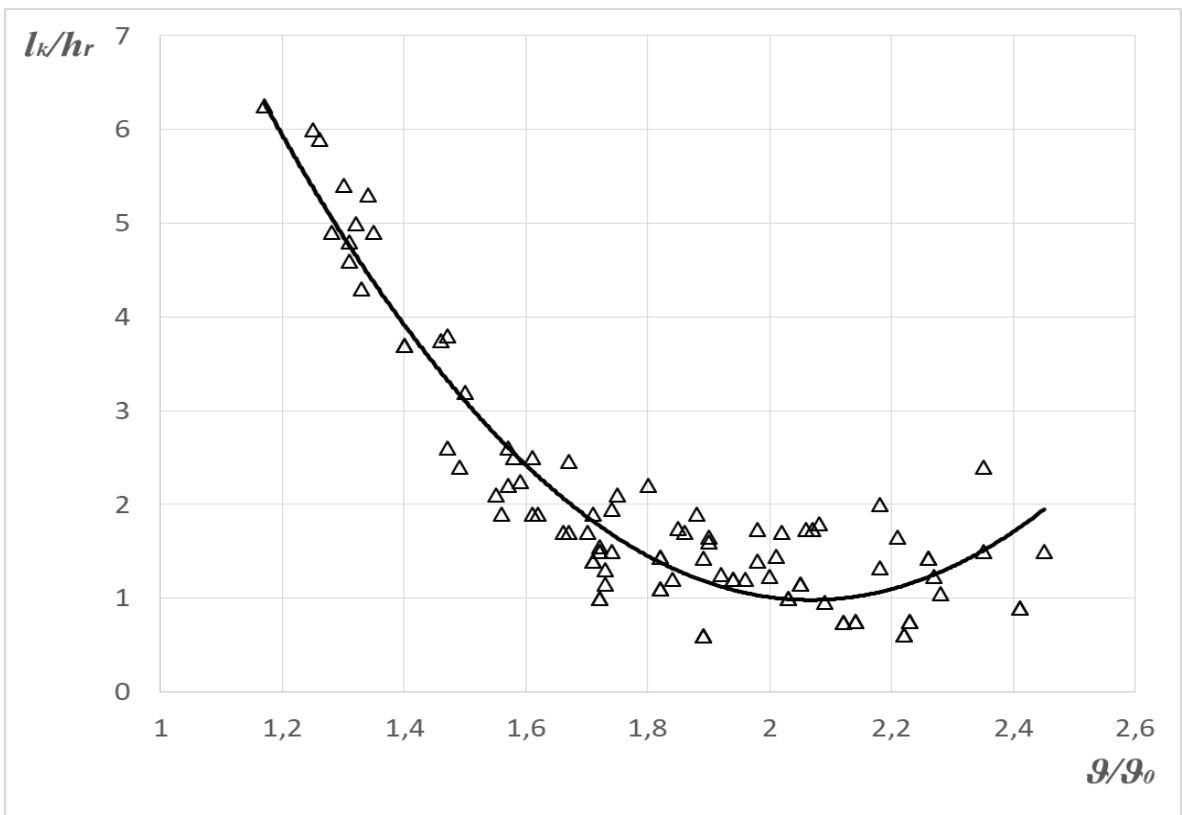

Fig. 3. Dependence of ridges relative steepness on the relative flow rate (sediments with mean diameters $0.31 \mathrm{~mm}, 0.80 \mathrm{~mm}, 1.62 \mathrm{~mm}, 1.55 \mathrm{~mm}, 2.53 \mathrm{~mm}, 2.50 \mathrm{~mm}, 4.03 \mathrm{~mm}, 4.0 \mathrm{~mm}$, and spatial model of the Main canal diversion)

From formula (3), may determine the ridge steep length:

$$
l_{k}=h_{r}\left(6,594\left(\frac{\vartheta}{\vartheta_{0}}\right)^{2}-27,26 \frac{\vartheta}{\vartheta_{0}}+29,1\right)
$$

The ridge height is determined by the formula $(31,32)$ : 


$$
h_{\mathrm{r}}=d\left(-4,38 \cdot e^{0,23 \cdot \varepsilon} \cdot\left(\frac{\vartheta}{\vartheta_{0}}\right)^{2}-\left(9,2 \varepsilon^{2}-35,8 \varepsilon-12,7\right) \cdot\left(\frac{\vartheta}{\vartheta_{0}}-1,1\right)\right)
$$

here: $\mathrm{d}$ is the sediment mean diameter; $\vartheta$ and $\vartheta_{0}$ are average and non-eroding velocities of the flow; $\varepsilon$ is coefficient of sediments heterogeneity.

The ridge lower escarpment is always supported by the reverse currents of the whirlpool flow zone. The nature of the whirlpool zone is determined by the Froude number Fr and the mobility criterion $9 / \mathrm{W}(29)$. Therefore, the ratio of the average flow velocity $9 / \vartheta_{0}$ to the non-eroding one was taken as a parameter determining the change in the position of the ridge lower escarpment.

As a result of statistical processing of our laboratory data and the Main canal diversion (MCD) spatial data model (Figure 4) using correlation obtained the following relation to calculate the magnitude of ridge lower escarpments with the magnitude of the correlation coefficient $\eta_{\mathrm{xy}}=0,83$ :

$$
m_{k}=10\left(\frac{\vartheta_{0}}{\vartheta}\right)^{2,85}
$$

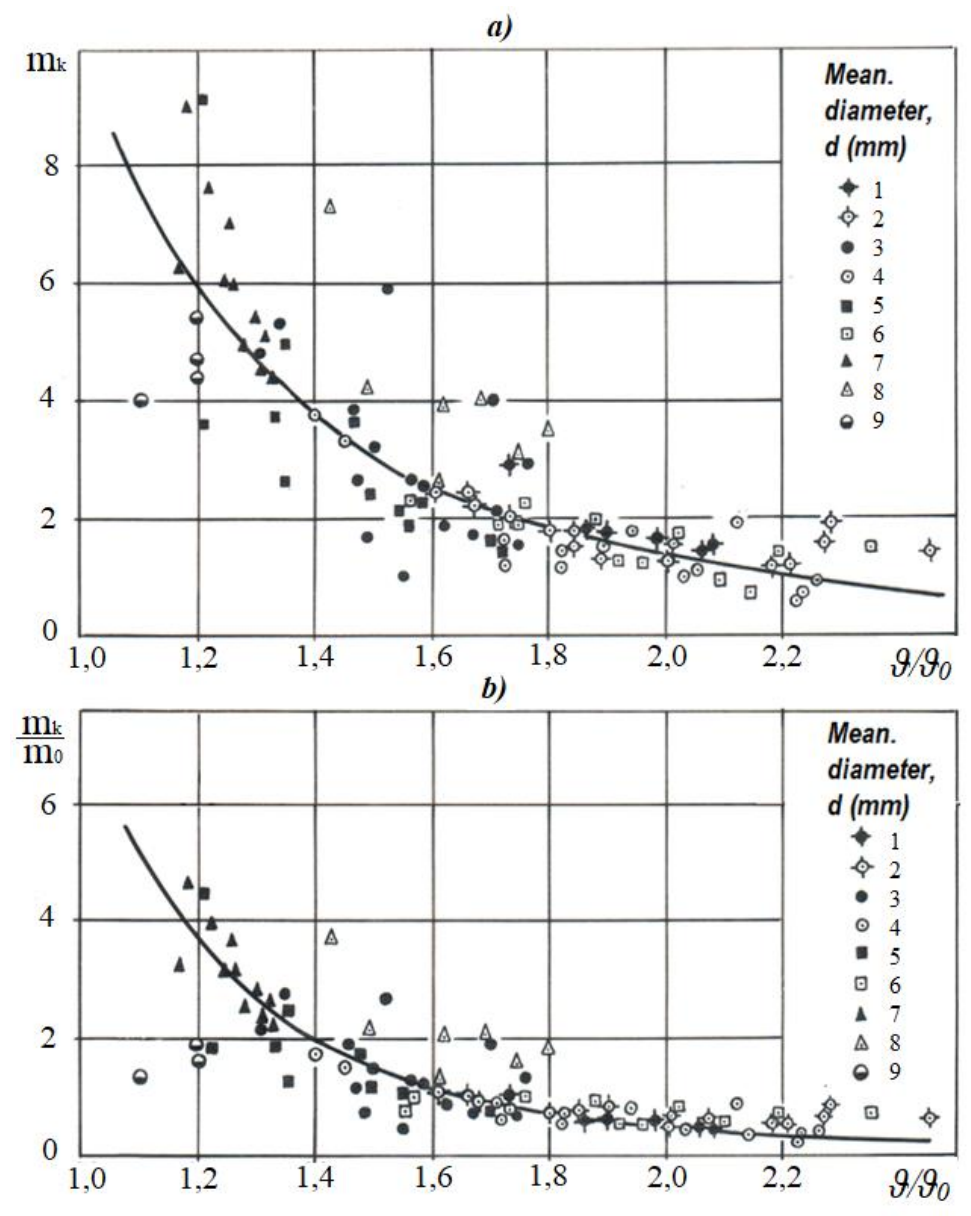

Fig. 4. Dependences of the absolute (a) and relative (b) coefficients of the ridge lower escarpment on the relative flow velocity: 
1- $0.31 \mathrm{~mm} ; 2$ - $0.80 \mathrm{~mm} ; 3-1.62 \mathrm{~mm} ; 4-1.55 \mathrm{~mm} ; 5-2.53 \mathrm{~mm} ; 6-2.50 \mathrm{~mm} ; 7-4.03 \mathrm{~mm} ; 8-4.0$ mm; 9 - spatial model of the MCD.

The analysis of the graphical relationship in Figure $4 \mathrm{a}$ shows that the ridge lower escarpment coefficient $\left(m_{K}\right)$ is inversely proportional to the velocities ratio $\vartheta / \vartheta_{0}$, i.e., with a flow rate increase, the ridge lower escarpment becomes steeper. Within values of the lower escarpment coefficient $\mathrm{m}_{\mathrm{K}}=0.1 \div 1.0$, the ridge is washed away.

To determine values of the lower escarpment coefficient through values of the natural escarpment coefficient of materials, the dependence graph was constructed:

$$
\frac{m_{k}}{m_{0}}=f\left(\frac{\vartheta}{\vartheta_{0}}\right)
$$

Figure $4 \mathrm{~b}$ shows the curve constructed from experimental points that are described by the dependency:

$$
\frac{m_{k}}{m_{0}}=7,6\left(\frac{\vartheta}{\vartheta_{0}}\right)^{3,9}
$$

The correlation coefficient of the dependence (8) according to the results of statistical processing is equal $\eta_{x y}=0,85$. Using the dependence (9) may establish the relationship to determine the ridge lower escarpment coefficient, taking into account the natural escarpment coefficient of materials $\mathrm{m}_{0}$ :

$$
m_{k}=7,6 m_{0}\left(\frac{\vartheta}{\vartheta_{0}}\right)^{3,9}
$$

The natural escarpment coefficient of materials is determined by dependencies:

- under water:

$$
m_{0}=\frac{2,33}{d^{0,14}}
$$

- for dry ground conditions:

$$
m_{0}^{1}=\frac{1,71}{d^{0,06}}
$$

The graphical dependence analysis in Figure 4 shows that the velocity ratio increase $\vartheta / \vartheta_{0}$, escarpments coefficients ratio decreases. Thus, may distinguish three stages of the ridge lower escarpment formation:

I. stage - the value of the ridge lower escarpment coefficient is higher than the natural escarpment coefficient of experimental materials at $\vartheta / \vartheta_{0}=1,0 \div 1,5, m_{K}>m_{0}$ or $\mathrm{m}_{\mathrm{K}} / \mathrm{m}_{0}>1,0$.

II. stage - the value of the ridge lower escarpment coefficient and the natural escarpment coefficient of experimental materials are equal at $\vartheta / \vartheta_{0}=1,5 \div 1,6, \mathrm{~m}_{\mathrm{K}}=$ $\mathrm{m}_{0}$ or $\mathrm{m}_{\mathrm{K}} / \mathrm{m}_{0}=1,0$.

III. stage - the value of the ridge lower escarpment coefficient is less than the natural escarpment coefficient of experimental materials at $\vartheta / \vartheta_{0}=1,6 \div 2,8, \mathrm{~m}_{\mathrm{K}}<\mathrm{m}_{0}$ or $\mathrm{m}_{\mathrm{K}} / \mathrm{m}_{0}<1,0$.

A further decrease in the ratio of escarpment coefficients $\mathrm{m}_{\mathrm{K}} / \mathrm{m}_{0}$ with a corresponding increase in the velocity ratio $\vartheta / \vartheta_{0}$ leads to ridges washing. Figure 3.46 shows marked stages of the change in the schematized ridge lower escarpment depending on the change in the 
velocity ratio $\vartheta / \vartheta_{0}$. The ridges forms belonging to the III stage formation of the lower escarpment were obtained in the studies of Tsubaki and Nagai.

The spread of the experimental points (Figure 4) is explained by the fact that in some experiments, the lower escarpment characteristics, i.e., the ridge steep lengths, were measured after the experiment or after emptying the tray. Under such conditions, the influence of reverse vortex currents (under the influence of which the ridge lower escarpment is maintained) disappears, which leads to dislodging of the experimental material under the own weight influence. Thus, the ridge lower escarpment is given the natural steepness. Therefore, measurements of the ridge lower escarpment elements should be made before the experiment ending during the ridges functioning.

The position and change of the ridge lower escarpment depend on characteristics of the whirlpool zone reverse currents, so in future studies, special attention should be paid to establishing more strict quantitative relationships between the ridge lower escarpment shape and the whirlpool zone characteristics.

\section{Conclusions}

The study of the flow hydraulic characteristics influence on the ridge lower escarpment coefficient led to the following conclusions:

1. With a change in the hydraulic elements of the flow, the ridge lower escarpment value also changes. The position of the lower escarpment depends on the flow kinematic (velocity) characteristics.

2. With a change in the velocity ratio $\vartheta / \vartheta_{0}$, the ridge lower escarpment takes different positions. At the $9 / \vartheta_{0}=1.0 \div 1.5$, it is less than natural escarpment of materials, in the range, $\vartheta / \vartheta_{0}=1.5 \div 1.6$ is equal to the natural escarpment of the ground, and with the further increase in the range $\vartheta / \vartheta_{0}=1.6-2.8$, it is more than natural escarpment of materials.

3. The formula is derived to determine the ridge lower escarpment with and without taking into account the angle of the natural escarpment of the ground under water and dry ground condition.

4. The graphical dependence $l_{\kappa} / h_{r}=f\left(\vartheta / \vartheta_{0}\right)$ and formulas for determining the ridge steep length are obtained.

5. Three stages of the ridge lower escarpment formation are identified.

6. Following the dependencies (6), (8), and (9) established by us, the steepness of the ridge lower escarpment increases with the increasing flow velocity. At low flow rates, the steepness of the ridge lower escarpment is less than the natural escarpment of the experimental materials, and at high velocities, it is more.

\section{References}

1. Knox, R.L., Latrubesse EM. A geomorphic approach to the analysis of bedload and bed morphology of the Lower Mississippi River near the Old River Control Structure. Geomorphology. 2016;268:4-35.

2. Gunsolus EH, Binns AD. Effect of morphologic and hydraulic factors on hysteresis of sediment transport rates in alluvial streams. River Res Appl. 2018;34(2).

3. Graf WH. Hydraulics of sediment transport. Hydraul sediment Transp. 1984;

4. Bazarov, D., Vatin, N., Bakhtiyor, O., Oybek V. Hydrodynamic effects of the flow on the slab of the stand in the presence of cavitation. IOP Conf Ser Mater Sci Eng. 2021;1030.

5. Shaazizov F. Studies of turbulent flow characteristics of dividing open water streams. 
IOP Conf Ser Mater Sci Eng. 2021;1030.

6. E Kan, A Muratov, M Yusupov NI. Calculation of water hammer on the pressure pipeline of modernized irrigation pumping station. IOP Conf Ser Mater Sci Eng. 2021;1030.

7. Yan Y, Koplik J. Transport and sedimentation of suspended particles in inertial pressure-driven flow. Phys Fluids. 2009;21(1).

8. de Ruijsscher T V., Hoitink AJF, Naqshband S, Paarlberg AJ. Bed morphodynamics at the intake of a side channel controlled by sill geometry. Adv Water Resour. $2019 ; 134$.

9. L.G. Castillo, J.M. Carrillo JTG. Flow and sediment transport through bottom racks, CFD application and verification with experimental measurements. In: Proceedings of 2013 IAHR Congress Tsinghua University Press, Beijing. 2013.

10. Philip H. Alternating bar instabilities in unsteady channel flows over erodible beds. Mechanics. 2004;499:49-73.

11. Wang S, Flanagan DC, Engel BA. Estimating sediment transport capacity for overland flow. J Hydrol. 2019;578.

12. Palucis MC, Ulizio TP, Fuller B, Lamb MP. Flow resistance, sediment transport, and bedform development in a steep gravel-bedded river flume. Geomorphology. 2018;320.

13. Snishenko B. F., Mukhamedov A. M. MTS. Bedlam composition effect on dune shape parameters and on flow characteristics. In: International Association for Hydraulic Research //XXIII Congress, Ottawa. 1989. p. 105-12.

14. Yang CT, Marsooli R. Recovery factor for non-equilibrium sedimentation processes. $\mathrm{J}$ Hydraul Res. 2010 Jun;48(3):409-13.

15. S. N. Researches on the movement of the sang of the river bed of the Iyoga (in Japanese). Jour liv Eng Soci Japan. 1941;27(1).

16. Lu X, Wang X, Ban X, Singh VP. Transport characteristics of non-cohesive sediment with different hydrological durations and sediment transport formulas. J Hydrol. 2020;591.

17. Hino M. Eguilibrium - range spectra of sand waves formed by flowing water. Fluid Mech. 1968;34(3):565-73.

18. Dymshits E. A., Kromskaya T. P., Kostyuchenko I. P. SVG. Full-scale studies of sand waves. In: The movement of sediments in open channels. Moscow; 1970. p. 160-73.

19. G. S V. Experimental studies of the characteristics of the relief deformable bottom and the flow structure above it. Autoref. diss. for the academic degree.degrees of Candidate of Physical and Mathematical Sciences. Moscow; 1969. 20 p.

20. V. GK. Dynamics of channel flows. Gidrometeoizdat; 1979. 312 p.

21. Antsyferov S. M. DVK. Experimental study of the formation of solid flow in a ruslov flow. In: Movement of sediments in open channels. Moscow; 1970. p. 188-92.

22. Khetsuriani ED, Kostyukov VP, Ugrovatova EG. Hydrological Studies on the River Don around the Alexandrovsky OSV Water-Intake Facilities. In: Procedia Engineering. 2016. p. 2358-63.

23. Omid MH, Karbasi M, Farhoudi J. Effects of bed-load movement on flow resistance over bed forms. Sadhana - Acad Proc Eng Sci. 2010 Dec;35(6):681-91.

24. Curran JC, Waters KA, Cannatelli KM. Real time measurements of sediment transport and bed morphology during channel altering flow and sediment transport events. Geomorphology. 2015;244.

25. Verhagen ITE, Crisóstomo-Figueroa A, Utley JEP, Worden RH. Abrasion of detrital grain-coating clays during sediment transport: Implications for diagenetic clay coats. Sediment Geol. 2020;403.

26. Guo Q, Zheng Z, Huang L, Deng A. Regularity of sediment transport and 
sedimentation during floods in the lower Yellow River, China. Int J Sediment Res. 2020;35(1).

27. Khodzinskaya AG, Verbitskii VS. Determination of the Discharge of Bottom Sediments in River Beds Composed of Soil of Varying Grain Size. Power Technol Eng. 2019 Mar;52(6):669-74.

28. Samokhvalova OA. Calculation of the height of sand ridges in large and small plain rivers. Bull St Petersbg State Univ. 2011;4(7):135-48.

29. N.S. Z. Ridge movement of the sediments. L.: Hydrometeoizdat; 1968. 188 p.

30. Kopaliani Z. D. KAA. Calculations of the flow rate of bottom sediments in rivers. Collect Work Hydrol. 2004;27:25-40.

31. Ikramov N, Majidov T, Kan E, Ikromov I. The height of a damless water intake structure threshold. In: IOP Conference Series: Materials Science and Engineering. Institute of Physics Publishing; 2020. p. 072009.

32. Ikramov N, Majidov T, Kan E, Akhunov D. The height of the pumping unit suction pipe inlet relative to the riverbed bottom. IOP Conf Ser Mater Sci Eng. 2021;1030:012125. 